\section{AB0744 A "LOST-TO-FOLLOW-UP" AUTOANTIBODY FOR THE DIAGNOSIS OF AUTOIMMUNE DISEASE: PREVALENCE AND CLINICAL CHARACTERISTICS OF ANTI-NOR90/ HUBF POSITIVE PATIENTS}

C. Koutsianas ${ }^{1}$, K. Levasseur ${ }^{2}$, M. Rutter ${ }^{1}$, C. Webber $^{3}$, M. Bhole ${ }^{3}$, C. Bell ${ }^{2}$, K. Douglas ${ }^{1} .{ }^{1}$ Department of Rheumatology, The Dudley Group NHS Foundation Trust, Dudley, ${ }^{2}$ Department of Rheumatology, Worcestershire Acute Hospitals NHS Trust, Worcester, ${ }^{3}$ Department of Immunology, The Dudley Group NHS Foundation Trust, Dudley, UK

Background: Anti-nuclear antibody (ANA) patterns in indirect immunofluorescence testing (IIF) have been valuable in the diagnosis of autoimmune diseases. A pattern of speckling with fluorescent mitotic dots is considered to represent autoantibodies against nucleolar organising regions (NORs). Anti-NOR90 antibodies target the human upstream binding factor (hUBF) which activates RNA polymerase I-activated ribosomal RNA transcription. They have been anecdotally associated with systemic sclerosis (SSc), Sjögren's Syndrome (pSS) and rheumatoid arthritis (RA).

Objectives: To analyse the prevalence and clinical characteristics of patients found to be anti-NOR90 positive by immunology at The Dudley Group NHS FT (DGH) which also serves Worcestershire Acute Hospitals NHS Trust (WAH).

Methods: Clinical letters and electronic patient records of anti-NOR90 positive patients identified in the DGH immunology laboratory between July 2016 and October 2017 were reviewed. Advice was sought regarding ethical approval and consent; this was deemed unnecessary for this clinical survey. Anonymized patient data was collected on Excel. Anti-NOR90 was tested for when the characteristic ANA pattern was observed and as part of an extended SSc blot (EUROLINE SSc (Nucleoli) profile (IgG) - EUROIMMUN).

Results: We identified 11 anti-NOR90 positive patients among 8000 positive ANA results (estimated prevalence $0.0137 \%$ ). Patient demographics, diagnoses and immunology are illustrated in table 1. Patients were in their vast majority female (10/11, 91\%) and had a median age of 63 (IQR:53-74) years. The median anti-NOR90 titer was 111 (IQR:14-139) intensity units. 6/11 (54.5\%) had a confirmed diagnosis of rheumatic disease. The most common clinical features were Raynaud's phenomenon (63.6\%), sicca symptomatology (36.4\%) and polyarthritis (36.4\%). Interstitial lung disease (ILD) and oesophageal dysmotility (OD) were predominant clinical features in two cases (SSc, pSS). In general, patients lacked skin involvement (scleroderma, telangiectasias, calcinosis).

Abstract AB0744 - Table 1. Demographic, clinical and immunological characteristics of anti-NOR90 positive patients

\begin{tabular}{|c|c|c|c|c|c|c|}
\hline Patient & $\begin{array}{c}\text { Age/ } \\
\text { Sex }\end{array}$ & Diagnosis & $\begin{array}{c}\text { Rheumatoid } \\
\text { Factor }\end{array}$ & $\begin{array}{l}\text { ANA } \\
\text { titre }\end{array}$ & ANA pattern & $\begin{array}{c}\text { anti- } \\
\text { NOR90 } \\
\text { titre }\end{array}$ \\
\hline 1 & $82 / F$ & SSc & - & $\begin{array}{c}\text { weak } \\
\text { positive }\end{array}$ & mitotic dots & positive \\
\hline 2 & $\begin{array}{l}80 / \\
M\end{array}$ & pSS & - & $1: 320$ & $\begin{array}{c}\text { speckled mitotic } \\
\text { dots }\end{array}$ & 11 \\
\hline 3 & $35 / \mathrm{F}$ & UCTD & - & $1: 2560$ & $\begin{array}{l}\text { nucleolar with } \\
\text { mitotic dots }\end{array}$ & 140 \\
\hline 4 & $63 / F$ & RA & + & $\begin{array}{c}\text { weak } \\
\text { positive }\end{array}$ & mitotic dots & positive \\
\hline 5 & $81 / F$ & Bronchiectasis & - & $1: 1280$ & $\begin{array}{c}\text { speckled mitotic } \\
\text { dots }\end{array}$ & 107 \\
\hline 6 & 18/F & Raynaud's & - & $1: 1280$ & mitotic dots & 139 \\
\hline 7 & $68 / F$ & Raynaud's & - & $1: 320$ & $\begin{array}{l}\text { nucleolar with } \\
\text { mitotic dots }\end{array}$ & 130 \\
\hline 8 & $56 / \mathrm{F}$ & UCTD & + & $1: 320$ & mitotic dots & 11 \\
\hline 9 & $66 / F$ & Raynaud's & - & negative & negative & 14 \\
\hline 10 & $53 / F$ & $\begin{array}{l}\text { Raynaud's/ } \\
\text { Crohn's } \\
\text { disease }\end{array}$ & - & $1: 1280$ & $\begin{array}{c}\text { nucleolar } \\
\text { +homogenous with } \\
\text { mitotis dots }\end{array}$ & 151 \\
\hline 11 & $52 / F$ & Polyarthritis & - & $\begin{array}{c}\text { weak } \\
\text { positive }\end{array}$ & mitotic dots & 111 \\
\hline
\end{tabular}

Conclusions: Literature regarding anti-NOR90 auto-antibodies has been scarce and in the age of automated IIF ANA testing, it is plausible that their specific nucleolar pattern is frequently missed. In our survey, they were observed in the context of several rheumatic diseases and linked to Raynaud's, sicca symptoms and polyarthritis. Studies in larger relevant patient cohorts are needed to further clarify their clinical value.

Disclosure of Interest: None declared

DOI: 10.1136/annrheumdis-2018-eular.7422

\section{$\mathrm{AB} 0745$ \\ MECHANICS OF EARLY VENTRICULAR IMPAIRMENT IN SYSTEMIC SCLEROSIS AND THE EFFECTS OF PERIPHERAL VASCULOPATHY}

C. Tountas ${ }^{1,2}$, V.-K. Bournia' ${ }^{1}$, S. Panopoulos ${ }^{1}$, A. Gournizakis ${ }^{2}$, D. Beldekos ${ }^{2}$, M. G. Tektonidou ${ }^{1}$, A.D. Protogerou ${ }^{1}$, P.P. Sfikakis ${ }^{1} .{ }^{1}$ First Department of

Propaedeutic and Internal Medicine/Joint Rheumatology Program, "Laikon"

Hospital, School of Medicine, National and Kapodistrian University of Athens,

Athens; ${ }^{2}$ Cardiology Department, Tzaneio Hospital, Piraeus, Greece

Background: Multiple mechanisms commonly lead to severe cardiac involvement in systemic sclerosis (SSc), an autoimmune disease characterised by microvascular lesions, systemic inflammation and fibrosis.

Objectives: To examine the mechanics of right and left ventricles (RV, LV) at the early stage of possible impairment and test the hypothesis that peripheral arterial hemodynamics are associated with an early LV compromise.

Methods: Ninety-five asymptomatic SSc patients free of cardiovascular disease ( $88 \%$ women, $53 \pm 14$ years) and 54 apparently healthy controls matched for age gender, arterial hypertension, dyslipidaemia, and diabetes mellitus underwent echocardiography, including multilayer speckle-tracking, and tonometry-based pulse wave analysis of the peripheral arteries; 66 SSc patients were prospectively assessed after $32 \pm 7$ months. Indices of ventricular and arterial structure and function, as well as LV-arterial coupling, were calculated.

Results: At baseline, patients presented RV diastolic/systolic impairment, as well as $L V$ remodelling and diastolic/systolic impairment in terms of reduced deformation parameters versus controls. No association was evident between RV and LV strain within individual patients, whereas by multivariate analysis including age, gender and SSc characteristics we found that the global longitudinal strain of RV free wall was associated only with the presence of diffuse skin involvement $(b=2.63, p=0.042)$ and both global longitudinal and circumferential strain of LV were correlated only with disease duration $(b=0.14, p=0.001$ and $b=0.17$, $\mathrm{p}=0.032$, respectively). Both $\mathrm{RV}$ and $\mathrm{LV}$ abnormalities progressed independently during follow-up. Moreover, in the absence of differences in aortic stiffening and LV-arterial coupling between patients and controls, arterial pressure wave reflections assessing small vessel function and/or microcirculation were abnormal in SSc patients and strongly correlated with impaired indices of $L V$ diastolic function and remodelling.

Conclusions: These novel findings show the mechanics of RV early impairment in SSc that develops and progresses independently from the concomitant LV impairment, which, in turn, may be influenced by peripheral microvascular abnormalities in the absence of macrovascular damage.

Disclosure of Interest: None declared

DOI: 10.1136/annrheumdis-2018-eular.4442

\section{$\mathrm{AB} 0746$ \\ FREQUENCY AND CLINICAL ASSOCIATION OF RARE ANTIBODIES IN A LARGE CONNECTIVE TISSUE DISEASE COHORT}

C. Campochiaro, K. Clark, L. Host, A. Sari, S. Nihtyanova, C. Fonseca, C. Denton, V. Ong. Centre for Rheumatology and Connective Tissue Diseases, The Royal Free Hospital, London, UK

Background: Connective tissue diseases(CTDs) are characterised by the presence of specific antibodies(Abs). These are useful in diagnosis and prognostic stratification. Rare Abs have been reported but their clinical significance is currently not as clear.

Objectives: to assess the diagnosis, and frequency of clinical features within each rare antibody subgroup in our CTD cohort

Methods: The immunology results for 5828 patients obtained over the past 17 years and patients positive for 1 of the rare Abs (Jo-1, PCNA,XR,PL-4,PL-7,PL12,SRP, Ku,Mi-2,EJ,SL,PmScl,rRNP,Th/To,NuMa-1,OJ and hnRNP) were identified. Diagnosis and frequency of major organ involvement were reported.

Results: 758 patients(12.5\%) were positive for at $>1$ rare Abs. Clinical information confirming a diagnosis of a CTD was available for 514 patients. The most frequent rare $\mathrm{Ab}$ in our cohort was $\mathrm{PmScl}(3.10 \%)$. The majority of patients had clinical features of overlap syndromes(33.8\%), the 2nd most common diagnosis was systemic sclerosis(SSc)(31.10\%). Interstitial lung disease(ILD) was more commonly seen in patients with PL-7+(82.4\%), PL-12+(75\%), Jo-1+(70.8\%) and $\mathrm{SRP}+(66.7 \%)$. ILD was not reported in PCNA+,PL-4+, NuMA-1+and hnRNP+. Pulmonary arterial hypertension(PAH) was most frequently seen in patients with $\mathrm{XR}+(31.8 \%)$. Inflammatory myositis(IM) was found in all Jo1 + and SRP + patients, and in the majority of PL-7+(88.2\%) patients. Inflammatory arthritis was commonly reported in patients with PCNA+(57.1\%), NuMA-1+(50.0\%) and rRNP+(40\%) Renal involvement was classified as either glomerulonephritis(GMN) or scleroderma renal crisis(SRC). GMN was more common in patients with $\mathrm{rRNP}+(60 \%)$, $\mathrm{PL}-4+(45.4 \%)$ and $\mathrm{PCNA}+(42.9 \%)$ patients. SRC was diagnosed in patients with $\mathrm{SL}+(3.2 \%), \mathrm{PM} / \mathrm{Scl}+(5.5 \%)$ and $\mathrm{Th} / \mathrm{To}+(2.5 \%)$ (table 1$)$. 